\title{
The Influence and Enlightenment of Second Language Acquisition and Cognitive Theory on English Teaching in China \\ Weiwei Feng \\ Xi'an University 710065
}

Keywords: Second language acquisition; Cognitive theory; English teaching

\begin{abstract}
Second language acquisition and cognitive theory are of great significance to our English teaching. We must fully understand and apply the theory to guide English teaching. In English teaching, we must fully understand and deal with the role of students, the appropriate language learning environment, the correct choice of teaching content, teaching strategies and teaching activities.
\end{abstract}

\section{Second Language Acquisition Theory}

Concept. The American linguist Krashen explains the theory of second language acquisition like this: for language learners in any age groups, language learning usually has two ways, namely acquisition and learning. Acquisition means that the learners obtain information through language learning. Through communication and in contact with the outside world, learners can express their views through their subconscious understanding of the language. This kind of learning method is subtle, and the learners are not easy to detect. Learning refers to learners' active and conscious activity of systematic learning of a language and to gain knowledge of the language. Learners can grasp the language properly only through learning rules and forms, and thus is able to use the language correctly.

Second language is different from foreign language. Second language acquisition is how people learn another language based on the mother tongue. Second language acquisition is a learning process, but whether the language is a second language depends on status of the language in the country. Therefore, in the teaching, teachers should distinguish the two languages correctly, teach scientifically. In general, the difference between foreign language and second language mainly depends on whether the language of learning and the native language of the learner belong to the same language family. Like Chinese and English, they belong to different two language families, because the English language feature and cultural background are completely different from those of Chinese, so we call English as a foreign language. However, according to China's current language environment and system, foreign language is only limited in the classroom. The second language acquisition theory combines learning and acquisition, improves the quantity and quality of language input, creates a realistic learning environment, and encourages students to have a great influence on individual learning.

\section{The Influence and Enlightenment of Second Language Acquisition Theory on English Teaching}

Discussion of English Teaching Concept. Traditionally, we all think that English is only an anxious communication tool, and students can use the knowledge they have learned to freely communicate with others. But with the development of globalization, facing the changes in the language environment, treating English as a communication tool has been insufficient to meet the needs of the moment. In essence, English is not only a communication tool, but also a culture, and is a mixture of social activities and thoughts. The user's way of thinking, the social system in which the user is located, and the user's own culture and tradition determine the way the user's English is used. The main goal and mission of English teaching is to cultivate outstanding professionals in the construction of the motherland. English teaching can make students master English and achieve the level of fluency. It can also help students to fully understand the cultural background of English and 
make students understand the way of thinking of English native speaker. Many people can speak English, such as people from the United Kingdom, the United States, or from other countries that speak English as the official language. In the context of English globalization, English teaching should fully teach students the English culture, society and way of thinking, and create an English language environment for students. In the whole process of English teaching, contextual knowledge is an indispensable element in language teaching. In fact, the communicative ability of a good language learner may meet some restrictions in the communication and encounter a lot of embarrassing situation due to the lack of understanding of contextual knowledge. The ultimate goal of English teaching in our country is to cultivate talents with cross-cultural thinking and use English proficiently, accurately and properly. In English teaching, we must pay attention to the changes in the English classroom learning environment. The classroom is an organism and a market, which will change with the external environment changes. The various factors in the language learning classroom are closely related to English teaching. Therefore, the language teaching classroom cannot be separated from the reality of social economy and culture.

The Language Acquisition Environment has a Decisive Influence on the Achievement of Foreign Language Acquisition. The differences between the monitoring theory, the environmental theory, the output theory of second language acquisition and the second language acquisition and the foreign language acquisition have fully proved that the language acquisition environment plays a decisive role in the proficiency of language acquisition. If there is no language environment, enough understandability of language input and output will be difficult to achieve. To cultivate language learners' foreign language communication skills, the necessary language education content should include tacit knowledge of cultural or thinking habits, language perception and the real language environment. It is very difficult for English learners to learn English in China, which is mainly because of the lack of real language environment. We cannot change the language environment in China, nor can all the English learners are studying abroad, then we can only create a real and dynamic language learning environment for language learners to facilitate and reduce resistance. With the development of science and technology, computer and network technology provide technical support for the creation of language environment. English learning language environments mainly include classroom learning environment and extracurricular learning environment. The input theory in the monitoring theory clearly points out that the language acquisition should have enough input and quality, which is the inevitable requirement of the extracurricular learning environment. In such a language environment, language learners can arrange their own time by virtue of their own preferences to choose a variety of language learning related scene, and can also be in real language environment to practice their own voice and statement. The positive effect of classroom environment learning and extracurricular language environment on language learners can not only improve the students' ability of using English comprehensively, but also expand the view of language learners, increase the knowledge of language learners, and can timely supplement the language communicative knowledge for language learners. With the help of language environment, the rapid growth of language skills will facilitate the intrinsic learning motivation of the language learners, prompting learners to be harder to learn, thus forming a long and healthy cycle in the motivation and learning outcomes.

Curriculum Setting, Teaching Material Quality and Teacher's Ability to Influence the English Teaching Effect in China. English learning environment in China, viz. second language acquisition environment, should be called a foreign language learning environment. The English classroom learning environment is the most important in this foreign language learning environment. The most important place for Chinese students to learn English is classroom learning. The classroom environment directly affects whether students can complete their own language acquisition goals. Lot of researches and experiences confirmed that classroom teaching has a great promoting role on language acquisition. In China, English is widely used as a foreign language, so the classroom teaching on the promotion of English learning cannot be underestimated. And the quality of the classroom environment related to the curriculum, teaching quality and teaching ability of teachers should be obtained a high degree of attention. Therefore, in the curriculum setting 
should follow the scientific and reasonable laws consistent with the language acquisition, select high-quality, rich real content and subject matter to meet the needs of students on the textbook, and English teachers must be both theoretical and practical and have reasonable knowledge structure. Only in this way can teachers greatly improve the quality of English classroom teaching, thus promoting language learners to have a great improvement. This also shows that English teachers with both ability and political integrity who follow the language acquisition and teaching rules of the curriculum, high-quality teaching materials are also an integral part of the success in English teaching in China.

\section{The Theory of Cognition}

The Main Concept. The famous philosopher, epistemologist, psychologist and educator Piaget put forward the theory of cognition, which combines psychology and epistemology, and makes a new interpretation of knowledge and intelligence. The theory also reveals the process of intelligent development and emphasizes the dynamics of awareness activities, the initiative of the main body and the importance of interaction with the environment, which has important significance for educational activities

The purpose of English teaching should cultivate and improve students' ability to use English comprehensively, cultivate students' logical thinking and independent thinking ability of language communication, and improve students' language skills. English learning involves language, psychology and cognition. Cognitive theory lays the theoretical foundation for the development of foreign language teaching. In English learning, teachers should change the embarrassing situation of the past high input and low input. Teachers have to find ways to enable students to internalize the knowledge, which requires teachers to focus on teaching methods of research, fully understand the teaching and learning. Learning is the process of continuous accumulation of knowledge. Students should learn to consolidate and process their own knowledge and future input of the knowledge and establish relevance in the old and new knowledge, and this process is actually analysis, sorting and induction of the learners' knowledge. In this process, learners fully use the cognitive theory to guide their English learning. Therefore, English teachers should also use the cognitive theory to guide students to learn English in English teaching.

\section{The Influence and Enlightenment of Cognitive Theory on English Teaching}

Reposition of the Student's Role in English Teaching. In the process of English teaching, we need to change the traditional teacher-centered teaching, regard the students as a recipient of knowledge, fully respect for the student's dominant position, and play students' dominant role. Therefore, in the daily English teaching, the English teachers, should create a positive language learning situation as far as possible for students to guide students to actively explore the study without restriction of students' learning activities. Too many restrictions on student learning activities will seriously hinder students to play the main role, and also depress the creative ability of students to play. Only recognizing the effect of learning brought by students spontaneous learning can English teachers correctly handle the relationship between teachers and students in the classroom and recognize the leading role of teachers and the main role of students.

The Enlightenment of the Choice of English Teaching Content. In English teaching, how can English teachers know what kind of teaching content will be appropriate for students to stimulate? How to organize and deal with teaching content to enable students to easily receive and absorb? Different students of diverse stages have various cognitive structures. Therefore, English teachers should choose the teaching contents according to the different characteristics of the students. English teachers should combine the students' life experience and the students' understanding of the social function of the language and the classroom knowledge together so that the students' language learning becomes more natural and more appropriate. In English teaching, English teachers should use a variety of teaching materials, such as textbooks, physical information, pictures, audio and video information, etc., to improve students' interest in English learning and encourage students to 
actively participate in teaching activities. The full use of audio and video data will receive better learning results, especially in the oral English and listening class.

The Enlightenment of English Teaching Strategies and Teaching Activities. Students are the main body of learning activities. Heuristic teaching strategies should be chosen in the English teaching to encourage students to actively think, dare to say, dare to do, so as to make English learning become relaxed and interesting activities that everyone wants to participate. Therefore, the English teacher cannot treat the students as a simple machine and cannot randomly increase the teaching content beyond the cognitive structure of students to improve the student's scores. This will be easy to lead to the disorder of students' the original cognitive structure. Therefore, teachers must refer to the ability of students in the choice of teaching strategies and teaching activities.

In English teaching, English teachers should continue to provide students the contents that are related to the existing experience, and also to provide the students the contents that are contradictory to the existing experience. This can both consolidate the original knowledge and experience and promote the students to produce known and unknown contradiction, to break the balance of the original state of the students, thus making students' cognition from balance to imbalance and then to balanced state. With the continuous development, students will take an interest in knowledge and desire to learn, which can make students voluntarily receive the help of teachers, sum up the existing knowledge, process and absorb the new knowledge, resolve the contradiction between old and new knowledge, and ultimately enable the students to achieve a balance between old and new knowledge.

In English teaching, teachers should pay attention to student activities. Piaget's cognitive theory holds that knowledge comes from action and knowledge comes from activity. Therefore, the English teachers should encourage students to develop a multi-brain, more hands-on, more good habits of learning, and through activities to improve students' knowledge of English and skills to master the degree. Any teaching activities are bilateral activities of teachers and students. It is not enough to only rely on the teacher's lecture, but also needs the active participation of students. Language is a communication tool. Only by continuous use in real life can language ability be getting better development. English teachers should do a good job in teaching activities, for example, using the way of group activities to improve students' oral and listening ability. Teachers can also design different learning tasks for students to complete based on teaching content and students' life experience. In the process of completing the task, students will actively collect and sort out the information, energetically discuss and exchange views with classmates, and actively express their point of view. In this process, the students' language knowledge and skills have been greatly improved. In the teaching activities, teachers should not correct the grammatical mistakes of students' oral communication excessively, but should pay attention to the fluency of students' oral expression and pursue the accuracy on the basis of fluency, thus to avoid the students to be trapped in a cycle of dumb English.

Cooperative learning is the main method of learning in cognitive theory. Both partners can be greatly improved through the cooperation with others. In English teaching, teachers should respect students and encourage students to cooperate, rather than compete with each other. In the process of cooperation, a good relationship of cooperation will be formed between teachers and students and between students and students. In the process of cooperation, it not only cultivates the students of the collectivist spirit and exploring spirit, but also improves students' interest in learning English and motivation.

Students' self-regulating ability should be cultivated in English teaching. Teachers should use the usual teaching activities to continuously teach students to learn strategies and methods to enable students to know how to adjust the knowledge, integration and control, and thus enable students to learn the free use of knowledge rather than simply rote. The teachers should help students improve their ability to self-regulate by helping students to self-understand, determine the English learning goals and monitor and regulate themselves. When students no longer regard learning as a burden, but to treat learning as their own internal needs, the English teaching work is really completed from the teacher's teaching to student's learning. 


\section{Conclusion}

Both second language acquisition theory and cognitive theory sufficiently explain that the teachers should fully respect the student's dominant position for and create a good classroom learning environment and a good extracurricular acquisition environment of second language acquisition for students. English teachers also should continue to make self-improvement, perfect the English teaching methods and strategies to promote the continuous development and improvement of English teaching.

\section{References}

[1] J. Piaget: The Langhage and Thought of the Child (Cultural Education Press, China 1980).

[2] Y.H. Chen: Cognitive Psychology (Zhejiang People's Publishing House, China 1997). (In Chinese)

[3] K.C. Feng: Selection of Cognitive Structure and Epistemology Theory (China Environmental Science Press and Xueyuan Audio-visual publishing House, China 2006) (In Chinese)

[4] J.X. Fu: The Significance of Piaget's Theory to Education and Teaching. Journal of Qinzhou Teachers College, Vol. 14 (1999) No. 2, p. 62. (In Chinese)

[5] X.Z. Zhuang: Piaget Theory and Education Reform--Some Inspirations from Re-reading Piaget's Works in Chinese Translation. Journal of Changzhou Teachers College of Technology, Vol. 7 (2001) No. 3, p. 8. (In Chinese)

[6] J.M. O'Malley and A.U. Chamot: Learning Strategies in Second Language Acquisition (Cambridge University Press, British 1990).

[7] C.L. Zhang: The Application of Contemporary Cognitive Psychology in Teaching (Southwest China Normal University Press, China 1996). (In Chinese)

[8] B.J. Wadsworth: Piaget's Theory of Cognitive and Affective Development (Xiamen University Press, China 1989).

[9] X.H. Ma: A Preliminary Study on English Education for Preschool Children. Journal of Basic English Education, (2001) No. 4, p. 99. (In Chinese)

[10]B. Huang: An Introduction to Second Language Acquisition (Guangdong Higher Education Press, China 2004). (In Chinese)

[11]X.W. Zhou: Of Second Language Acquisition for College English Teaching and Learning. Journal of Legends and Biographies, (2010) No. 1, p. 78. (In Chinese)

[12]L. Chen: On the Inspiration of Krashen's Theory of Second Language Acquisition to College English Teaching. Overseas English, (2010) No. 8, p. 17. (In Chinese)

[13]T.Y. Jiang and Q. Liu: How to Improve the Quality of English Classroom Teaching from the Perspective of Second Language Acquisition. Time Education, (2011) No. 4, p. 116. (In Chinese) 